\title{
Complications during Vaginal Hysterectomy: How to get over Them?
}

\author{
${ }^{1}$ Anuja Bhalerao, ${ }^{1}$ Anjali Kawthalkar, ${ }^{2}$ Sunita Ghike, ${ }^{3}$ Sulabha Joshi \\ ${ }^{1}$ Associate Professor, Department of Obstetrics and Gynecology, NKP Salve Institute of Medical Sciences and \\ Lata Mangeshkar Hospital, Nagpur, Maharashtra, India \\ ${ }^{2}$ Professor, Department of Obstetrics and Gynecology, NKP Salve Institute of Medical Sciences and \\ Lata Mangeshkar Hospital, Nagpur, Maharashtra, India \\ ${ }^{3}$ Professor and Head, Department of Obstetrics and Gynecology, NKP Salve Institute of Medical Sciences and \\ Lata Mangeshkar Hospital, Nagpur, Maharashtra, India
}

Correspondence: Anuja Bhalerao, Associate Professor, Department of Obstetrics and Gynecology, 494, Old Ramdaspeth Nagpur-10, Maharashtra, India, Phone: 0712-2427026, 09823680572, e-mail: vivek_bhalerao@yahoo.com

\section{ABSTRACT}

Today vaginal hysterectomy is the most commonly performed gynecological surgery for prolapsed uteri and for other conditions, like fibroid, dysfunctional uterine bleeding, cervical intraepithelial neoplasia, etc.

Vaginal hysterectomy has least incidence of complications. Complications like hemorrhage, infection, bladder injury, etc. are known.

This prospective study was carried out at a tertiary hospital to analyze the complications and find measures to prevent or decrease complications.

Primary hemorrhage was the most common complication, followed by bladder injury and infection. Thus proper selection of cases, preoperatively prepare for any eventuality and intraoperative proficiency can decrease vaginal hysterectomy complications.

Keywords: Vaginal hysterectomy, Complications.

\section{INTRODUCTION}

Hysterectomy is the most commonly performed gynecological surgery which has excellent long-term results, and it would be prudent to select options of hysterectomy with least complications.

Advances in medical field are going at a great speed, and so advances and innovations in surgery led to resurgence in learning with respect to descent of uterus, volume of uterus and history of previous surgeries, as it is the need of the hour.

Previously $80 \%$ hysterectomies were done abdominally but now more than $70 \%$ of the hysterectomies are done by vaginal route because the complications are $70 \%$ less as compared to abdominal route of hysterectomy.

Vaginal hysterectomy dates back to $120 \mathrm{AD}$ according to medical historian Leonardo, ${ }^{1}$ when Soranus did a vaginal hysterectomy for the first time and since then it has been refined by Baudelocque (1800), Recamier (1829), Pean, Schroeder, Schuchardt, etc.

No surgery is $100 \%$ safe and, even in best of hand, complications are known. Route of hysterectomy thus cannot be generalized and individualization of case is important to minimize complications by constant process of evolution and learning upholding the principles of modern medicine.

\section{AIMS AND OBJ ECTIVES}

This prospective study was carried out for over 2 years in a tertiary rural hospital.

- To evaluate the complications in vaginal hysterectomies
- To analyze and formulate strategies to prevent or minimize complications.

\section{MATERIALS AND METHODS}

- Vaginal hysterectomies for proposed uteri were grouped as group A (Table 1)

- Vaginal hysterectomy for other indications, like fibroid, adenomyosis, dysfunctional uterine bleeding, cervical intraepithelial neoplasia, etc. were grouped as group B (Table 2).

\section{Table 1}

Distribution of women in group $\mathrm{A}$

III prolapse with cystocele, enterocele, rectocele (vaginal hysterectomy with anteroposterior repair)

Procidentia with vaginal eversion

Vaginal hysterectomy with anterioposterior repair with pelvic

floor repair with sacropinous colpopexy

Patients with previous cesarean section, sling (virkud)

Total

126

Table 2

Indications for nondescent vaginal hysterectomy in group B

\begin{tabular}{|lr|} 
Fibroid uterus & 86 \\
DUB & 44 \\
Adenomyosis & 12 \\
CIN III & 4 \\
\hline Total & 146 \\
\hline
\end{tabular}


Various factors, like epidemiological, education, literacy, indication for hysterectomy, selection criteria, intraoperative complications, postoperative complications were noted and analyzed (Table 3).

Exclusion criteria for group B were:

- Previous two cesarean sections

- More than 16 weeks size uterus

- Endometriosis.

\section{\begin{tabular}{l|l} 
Table 3 & $\begin{array}{l}\text { The epidemiological factors, preoperativ } \\
\text { transfusion and duration of surgeries }\end{array}$
\end{tabular}}

\begin{tabular}{|lll|}
\hline & Group A & Group B \\
\hline Average age & $50-60$ years & $30-50$ years \\
Literacy & Uneducated & $<6$ th grade \\
Socioeconomic status & Low & Low \\
Preoperative blood transfusion & $36 \%$ & $6 \%$ \\
Duration of surgery & 2 hours & $40-90$ minutes \\
\hline
\end{tabular}

\section{DISCUSSION}

Vaginal hysterectomy is a discipline in itself, and quality of life consideration is our main aim while doing a surgery (Table 4).

\begin{tabular}{|c|c|c|}
\hline $\begin{array}{l}\text { Complicati } \\
\text { and in pos }\end{array}$ & uring vagin & sterectomy \\
\hline & Group A & Group B \\
\hline Hemorrhage & 4 & 1 \\
\hline Bladder injury & 1 & 2 \\
\hline Bowel injury & - & - \\
\hline Fever & 8 & 1 \\
\hline Numbness in legs & 3 & 2 \\
\hline Secondary hemorrhage & 9 & 2 \\
\hline Laparotomy & 1 & 3 \\
\hline Vault prolapse & 3 & - \\
\hline Total & 29 & 11 \\
\hline
\end{tabular}

Proper selection criteria and preoperative preparation should be done as follows:

\begin{tabular}{|c|c|}
\hline Group A & Group B \\
\hline $\begin{array}{l}\text { - } \text { Treat medical problems } \\
\text { - } \\
\text { - } \text { Packing } \\
\text { - } \\
\text { - Ustrogen cream } \\
\text { Ulcer should be healed } \\
\text { Investigations, preanesthetic } \\
\text { check-up. }\end{array}$ & $\begin{array}{l}\text { - } \text { Descent } \\
\text { - } \text { Volume } \\
\text { - } \text { Exansverse space } \\
\text { to see mobility } \\
\text { - Investigations, preanesthetic } \\
\text { check-up }\end{array}$ \\
\hline
\end{tabular}

Vaginal hysterectomy is done in dorsal lithotomy position and is associated with sciatic nerve, femoral nerve and peroneal nerve injuries.

In our study, five women had femoral palsy as compared to Dunniho $^{2}$ et al where they had femoral palsy in 33 women out of 1,762 women. This is due to compression and acute angulation of nerve as it passes below the inguinal ligament.

Rest, reassurance, analgesics and physiotherapy ${ }^{3}$ given to our patients and they went home well.
Incidence of ureteric and bladder injuries is 1/1000 and 0.01/ 1000 in vaginal hysterectomies. ${ }^{4}$ During vaginal hysterectomies, bladder and ureteric injuries are the main cause of litigation as bladder is prone to injury while separating it from cervix.

Review says that bladder complications are minimum in vaginal hysterectomies. In our study, three women out of 286 had bladder injuries and we had to do a laparotomy to suture bladder in two of them.

This complication can be minimized by catheterization during surgery from time to time and in women with previous cesarean section or during surgery when we go in more cervical depth to use the surgical window (vescico cervical space) to get the right plane as the bladder is loose in its lateral fifth. Thus, familiarity with anatomy, perseverance and surgical window minimizes mishaps.

Ureters are at risk in 0.01/1000 cases which can be prevented during vaginal hysterectomy by:

- Applying utero sacrals, Mackenrodt's after bladder retraction

- Do not clamp blindly when the uterine artery clamp slips

- In cases with previous cesarean section and massive prolepses be careful

- In cases with distorted anatomy and sagging uterines in fibroid.

Hemorrhage is the most common complication in any surgery and vaginal hysterectomy is no exception (Table 5).

Table 5 Incidence of hemorrhage in our study and others

\begin{tabular}{|lll|} 
& Group A & Group B \\
\hline Present study & $4 / 140$ & $1 / 146$ \\
& $8 / 280$ & $2 / 292$ \\
Mintz $^{5}$ & $12.5 \%$ & $5 \%$ \\
Seth $^{6}$ & & $2.4 \%$ \\
Weber $^{7}$ & $1.4 \%$ & $72 / 2940$ \\
\hline
\end{tabular}

Infiltrating cervix with vasoconstrictor before surgery reduces blood loss. ${ }^{8}$

Evaluate pedicles, never clamp blindly, identify and religate. If bleeding persists then do:

- Packing

- Embolization

- Internal iliac ligation.

Hemorrhage during surgery was evaluated using weight technique (weight of mops preoperatively and postoperatively). In two women in group A, we had to do internal iliac ligation.

Secondary hemorrhage was present in nine women and was treated with antibiotics. While doing vaginal hysterectomy we may need to do a laparotomy during eventuality. So, we should start with open minds and be prepared for a laparotomy in case of an eventuality (Table 6).

The laparotomies were done for two cases; bladder injuries and internal iliac ligation. In nondescent vaginal hysterectomy uterus at times is not favorably mobilized after uterines. In such patients trigger point clamp should be applied before any morsellation technique. Trigger point is a clamp applied medially after securing uterines on the broad ligament. This 


\begin{tabular}{ll} 
Table 6 & Incidence of laparotomy in our study and others \\
\hline Copenhaver $^{8}$, $^{2}$ oulamprat $^{9}$ & $6 / 1000,16 / 2106$ \\
White $^{10}$ & $2 / 300$ \\
Present Study & $4 / 286$ \\
Kem Hospital & $7 / 1762$ \\
Seth & $2 / 5344$ \\
Pratts $^{11}$ & $8 / 1218$ \\
\hline
\end{tabular}

secures vessels, decreases retrograde bleeding and mobilizes uterus.

\section{POSTOPERATIVE PERIOD}

Three women in group A had vault prolapse who were treated with vault repair.

Thus, during vaginal hysterectomy intraopartive obliteration of enterocele, doing a vault suspension and in women with external laxity a sacrospinous colpopexy ${ }^{12,13}$ can prevent vault prolapse at a later date.

\section{CONCLUSION}

Thus, difficult cases are of prolapse uteri for vaginal hysterectomy when there is long standing, massive prolapse with eversion of vagina and more uterocervical length. And in nondescent vaginal hysterectomy cases with restricted mobility, more volume, narrow pubic angle are difficult. Thus, proper selection of cases, preoperative preparation with knowledge, confidence steady, purposeful and determined actions and proficiency in variety of techniques is the key for a successful outcome during vaginal hysterectomy.

\section{REFERENCES}

1. Leonardo RA. History of gynecology, New York Foben press 1944.

2. Dunniho D. Huddleson H, North S. Femoral nerve palsy as complication of vaginal hyterectomy review of world literature. J Gynecol Surg 1994;10:1.

3. Seth S, Studd J. Vaginal hysterectomy 2002;345.

4. Harkki Sirenp, Joberg SJ, Titinen A. Urinary tract injuries after hysterectomy. Obstet gynecol 1998;92:113-18.

5. Mintz PD, Sullivan MF. Preoperative crossmatch ordering and blood use in elective hysterectomy. Obstet Gynecol 1985;65: 389-92.

6. Seth S, Studd J. Vaginal hysterectomy 2002;342.

7. Weber AM, Lee J. Use of alternative techniques of hysterectomy in ohio 1988-1994 N. Engl J Med 1996;335:483-89.

8. Copernaver EH. Vaginal hysterectomy: An analysis of indications and complications among 1000 operations. Am J Obstet Gynecol 1962;84:123-28.

9. Coulam CB. Pratt JH. Vaginal hysterectomy in previous pelvic operation contraindicated? Am J Obstet Gynecol 1973;116: 252-60.

10. White SC, Wartel LJ, Wade ME. Comparison of abdominal and vaginal hysterectomies: A review of 600 operations. Obstet gynecol 1971;37:530-37.

11. Pratt JH. Hysterectomy: Vaginal. In: Schaefer G, Raber EA (Eds). Complications in obstetric and gynecologic surgery, Hagerstown, Harper and Row 1981;376-88.

12. Morley GN, De Lancey JO. Sacrospinous ligament fixation for eversion of vagina. Am J Obstet Gynecol 1988;156: 872-79.

13. Symmonds RE, Pratt JH. Vaginal prolapse following hysterectomy. Am J obstet gynecol 1960;79:899-909. 